\title{
EDITORIAL
}

\section{Improving asthma treatment: the physiological message}

\author{
P.J. Sterk
}

During the past decade, there has been an enormous growth in the understanding of the fundamental abnormalities in the airways of patients with asthma. In particular, this relates to the allergen-driven inflammation within the airway wall. The safe application of fibreoptic bronchoscopy in asthma has allowed pathologists, immunologists and molecular biologists to investigate the interaction among the various resident cells and the inflammatory infiltrate in the mucosa and lamina propria [1]. At present, this approach seems to offer the best prospect for a gradual clarification of the pathogenesis of asthma. In addition, it can be envisaged that monitoring cellular presence [2], and activity [3], during therapeutic interventions will provide a rationale for the development of a more causal treatment of the disease. Hence, there is little doubt that the major improvements in future asthma therapy and prevention will be based on respiratory cell and molecular biology.

\section{Acute or chronic pathophysiology?}

It is remarkable that in contrast to a better understanding of the genesis and modulation of airway inflammation in asthma, it is still largely unclear which are the main effector mechanisms causing the enhanced airways obstruction in the disease. This is rather unexpected, since it has been an area of physiological research for many decades. Airways obstruction remains the functional characteristic that is responsible for the clinical expression of asthma [4]. Even though the degree and variability of airways obstruction appear to be associated with many markers of inflammation in the airways of asthmatics, the physiological factors determining the severity of airway narrowing are far from being clarified.

The currently available models of asthma are almost invariably based on acute or subacute pathophysiology, caused by various inducers of airway inflammation [5]. This applies for animal models as well as experimental human models of asthma. Such an approach is presently leading to the development of potentially powerful drugs in the prevention and reversal of acute inflammatory changes in the airways [6]. However, asthma is a chronic disease, and its pathophysiology might not be fully covered by these models.

Many tissue components appear to be able to contribute

Correspondence: P.J. Sterk, Lung Function Laboratory, C2-P, University Hospital Leiden, P.O. Box 9600, NL-2300 RC Leiden, The Netherlands. to the excessive and potentially life-threatening airway narrowing in asthma, including smooth muscle, airway nerves, bronchial vessels, connective tissue elements, mucosal or luminal exudates, and secretions [7]. Each of these can potentially be triggered by the various inflammatory pathways involved, but it has yet to be determined which of the effector mechanisms predominate in the various clinical presentations of asthma.

As a result of careful morphometry and physiological experiments, the functional importance of the chronic structural changes within the airways in asthma is now becoming apparent.

\section{Airway connective tissue elements}

In the "hypothesis" article in the present issue of the European Respiratory Journal, BRAMLEY et al. [8] strengthen the contribution of structural components within the airway wall, in particular of connective tissue, to the endorgan hyperresponsiveness in asthma. This is an area of great interest, particularly with regard to the long-term sequelae of the disease process. The very limited availability of tissue specimens obtained from patients with asthma has hampered rapid progress in this field. Indeed, the supportive evidence of BRAMLEY et al. [8] is only derived from data obtained in a single asthmatic subject. However, it is interesting, in view of hypothesis development, that the results presented provide an example of chronic abnormalities in structure of the airways in asthma.

The potential importance of the extracellular matrix may not be surprising, since chronic inflammation is associated with fibrosis and elastolysis [9]. This may alter the mechanical behaviour of the airways by changing the stiffness of the airway wall, which affects the load of the contracting smooth muscle [8] and the folding of the mucosa into the airway lumen [10]. In well-designed human in vivo experiments, BRACKEL et al. [11] have recently shown that there is, indeed, a difference between normal and asthmatic subjects in the compliance of the central airways. They concluded that the airways in asthma are relatively stiff, which might be due to oedema and/or fibrotic changes resulting from chronic inflammation. The results obtained with these indirect physiological techniques seem to contrast with those from the direct in vitro measurements by BRAMLEY et al. [8]. This might be due to the distinct methodologies, the limited number of experiments, or differences in stage of the disease process.

It should be emphasized that these mechanical events 
are not only of pathophysiological interest, since there is some recent evidence that therapeutic intervention can have beneficial effects on the nonmuscular components in asthma. Using bronchial biopsy specimens, DAvIES et al. [12] demonstrated by computer image analysis that the area of staining with a monoclonal antibody against collagen 3 in the subbasement membrane reticular layer was reduced after 4 months of inhaled steroid intervention. These observations warrant further attempts to develop strategies to prevent and reverse the structural changes in the airways in asthma.

\section{Amount of smooth muscle}

The most notable progress in understanding the increased severity of airway narrowing in asthma has been the recognition that the amount of smooth muscle is likely to be its major determinant. Certainly, enhancement of intrinsic contractility has also been observed in some, but not all, in vitro preparations of patients with asthma [13]. This might be due to elevated actomyosin adenosine triphosphatase (ATPase) activity within the smooth muscle cells, leading to an increase in shortening velocity and in maximum shortening capacity [14]. However, based on morphometric data of small airways in asthma and chronic obstructive pulmonary disease (COPD), detailed mathematical model studies by LAMBERT et al. [15] have indicated that the increased muscle mass is by far the most important abnormality responsible for excessive airway narrowing in these two disease entities. Taking the hypothesis of BRAMLEY et al. [8] into account, that the smooth muscle itself contributes to a relatively high compliance of the airway wall, it can be envisaged that smooth muscle hypertrophy or hyperplasia is, potentially, one of the major effector mechanisms determining the severity of airways obstruction in asthma.

These findings imply that further morphometric studies on the quantification of the amount of smooth muscle in the airway wall are needed, using various pathological techniques [8]. At present, the data indicate that investigation of the factors inducing airway smooth muscle hyperplasia and/or hypertrophy is a prerequisite for the development of successful therapeutic intervention in patients with excessive airway narrowing [16]. These factors may include a variety of cytokines and growth factors (interleukin-1 $\beta$, platelet-derived growth factor) [17], but also mediators such as: histamine, plateletactivating factor, endothelin-1, thromboxane- $\mathrm{A}_{2}$, and leukotriene- $\mathrm{D}_{4}[18,19]$. In this respect, much is to be learnt from cardiovascular research, in which the inducers of myointimal hyperplasia and its inhibitors have already been explored in more detail [20]. This kind of approach has already led to successful inhibition of airway smooth muscle proliferation in vitro, e.g. by heparin [21].

\section{Vessels and parenchyma}

Apart from smooth muscle mass and connective tissue elements within the airway wall, the severity of obstruction is also determined by the degree of submucosal and adventitial swelling, and by the mechanical interdependence between the airways and the lung parenchyma [15]. This concerns the microvasculature, with the capacity for angiogenesis [22], and microvascular leakage and congestion [23], during the chronic and acute inflammatory events in asthma. In particular, adventitial swelling can augment airway narrowing, by reducing the effectiveness of the elastic load on the smooth muscle provided by the lung parenchyma [24]. This mechanical interdependence between airways and parenchyma appears to be clinically relevant, since the elastic forces limit smooth muscle shortening in normal subjects [25], which might be disturbed not only in emphysema [26] but also in patients with asthma [27].

Finally, the traditional view that contractile elements in the lung are restricted to the airways has recently been challenged by the observations of LuDwig et al. [28]. They showed that aerosol bronchoconstrictor stimuli in dogs not only increase airway resistance, but also elevate the tissue viscance, which accounts for a large proportion of the increase in overall lung resistance. The acute changes in tissue viscance can either be due to parenchymal distortion [29], or to contractile elements within the lung parenchyma, e.g. in the interstitium or the peripheral vasculature. Again, the behaviour of these elements seems to be of clinical importance, since BRUSASCO et al. [30] recently demonstrated that this can be one of the determinants of excessive airway narrowing in man in vivo.

\section{Conclusion}

The availability of new techniques has facilitated rapid progress in the understanding of the cellular and molecular abnormalities in asthma. Hopefully, this will eventually lead to clarification of its pathogenesis and, subsequently, to strategies in the prevention of the disease. However, the development of new treatment modalities for patients already suffering from asthma requires the knowledge of the effector mechanisms in the endorgan determining the severity of airways obstruction.

Recent physiological studies have provided new information about the tissue elements that are responsible for disease severity. The results of these studies indicate that chronic structural changes within the lung are the main determinants of the excessive and potentially lifethreatening airways obstruction in asthma. These structural changes could be sequelae of chronic inflammation. However, their prevention and reversal will not necessarily be obtained by anti-inflammatory therapy with the currently available corticosteroids. This can be illustrated by the limited capacity of steroids to normalize the functional abnormalities in asthma, such as airway hyperresponsiveness [31].

Consequently, remodelling of the airways requires new approaches, that are only just being explored. This issue has recently been addressed by PAGE and BLACK [32]. The present challenge is to combine the new knowledge on physiology, morphology and the molecular basis of asth$\mathrm{ma}$, in order to develop rational therapeutic interventions. 


\section{References}

1. Holgate ST. Mediator and cytokine mechanisms in asthma. Thorax 1993; 48: 103-109.

2. Laitinen LA, Laitinen A, Haahtela T. A comparative study of the effects of an inhaled corticosteroid, budesonide, and a beta ${ }_{2}$-agonist, terbutaline, on airway inflammation in newly diagnosed asthma: a randomized, double-blind, parallel-group controlled trial. J Allergy Clin Immunol 1992; 90: 32-42.

3. Robinson D, Hamid Q, Ying S, et al. Prednisolone treatment in asthma is associated with modulation of bronchoalveolar lavage cell interleukin-4, interleukin-5, and interferon- $\gamma$ cytokine gene expression. Am Rev Respir Dis 1993; 148: 401-406.

4. National Heart, Lung, and Blood Institute, National Institutes of Health Bethesda, Maryland 20892. International consensus report on diagnosis and treatment of asthma. Eur Respir J 1992; 5: 601-641.

5. Wanner A, Abraham WM, James SD, Drazen JM, Richerson HB, Ram JS. Models of airway hyperresponsiveness. Am Rev Respir Dis 1990; 141: 253-257.

6. Alabaster VA, Moore BA. Drug intervention in asthma: present and future. Thorax 1993; 48: 176-182.

7. Sterk PJ. The determinants of the severity of acute airway narrowing in asthma and COPD. Respir Med 1992; 86: 391-396.

8. Bramley AM, Thomson RJ, Roberts CR, Schellenberg $\mathrm{RR}$. Excessive bronchoconstriction in asthma is due to decreased airway elastance. Eur Respir J 1994; 7: 337-341.

9. Bousquet J, Chanez P, Lacoste JY, et al. Asthma: a disease remodelling the airways. Allergy 1992; 47: 3-11.

10. Lambert RK. Role of bronchial basement membrane in airway collapse. J Appl Physiol 1991; 71: 666-673.

11. Brackel HJL, Pedersen OF, Overbeek SE, Bogaard JM, Kerrebijn KF. Central airway compliance in healthy subjects and in patients with asthma. Eur Respir J 1992; 5(suppl. 15): 254s.

12. Davies RJ, Trigg CJ, Wang J, et al. The effects of longterm beclomethasone dipropionate on pathological changes in the bronchial mucosa of mild asthmatics. Am Rev Respir Dis 1993; 147: A841.

13. Bai TR. Abnormalities in airway smooth muscle in fatal asthma. A comparison between trachea and bronchus. Am Rev Respir Dis 1991; 143: 441-443.

14. Jiang E, Rao K, Halayko AJ, Liu X, Stephens NL. Ragweed sensitization-induced increase of myosin lightchain kinase content in canine airway smooth muscle. Am J Respir Cell Mol Biol 1992; 7: 567-573.

15. Lambert RK, Wiggs BR, Kuwano K, Hogg JC, Paré PD. Functional significance of increased airway smooth muscle in asthma and COPD. J Appl Physiol 1993; 74: 2771-2781.
16. Hirst SJ, Twort CHC. The proliferative response of airway smooth muscle. Clin Exp Allergy 1992; 22: 907-915.

17. Souhrada M, Swades DE, Zelazny ET, Souhrada EF. Role of interleukin-1 $\beta$ on the proliferation of airway smooth muscle cells. Eur Respir J 1993; 69 (suppl. 17): $273 \mathrm{~s}$

18. Noveral JP, Rosenberg SM, Anbar RA, Pawlowski NA, Grunstein MM. Role of endothelin-1 in regulating proliferation of cultured rabbit airway smooth muscle cells. Am J Physiol 1992; 263: L317-L324.

19. Wang CG, Du T, Xu LJ, Martin JG. Role of leukotriene$\mathrm{D}_{4}$ in allergen-induced increases in smooth muscle in the rat. Am Rev Respir Dis 1993; 148: 413-417.

20. Dzau VJ, Gibbons GH, Cooke JP, Omoigui N. Vascular biology and medicine in the 1990s: scope, concepts, potentials and perspectives. Circulation 1993; 87: 705-719.

21. Kilefeather SA, Matin R, Perez A, Page C. Inhibition of airway smooth muscle proliferation by heparin, low molecular heparin and heparin sulphate. Eur Respir $J$ 1993; 6 (suppl. 17): 273s.

22. Widdicombe J. Why are the airways so vascular? Thorax 1993; 48: 290-295.

23. Persson CGA. Plasma exudation in the airways: mechanisms and function. Eur Respir J 1991; 4: 1268-1274.

24. Macklem PT. A hypothesis linking bronchial hyperreactivity and airway inflammation: implications for therapy. Ann Allergy 1990; 64: 113-116.

25. Okazawa M, Bai TR, Wiggs BR, Paré PD. Airway smooth muscle shortening in excised canine lung lobes. J Appl Physiol 1993; 74: 1613-1621.

26. Cheung D, Merkenhof WM, Schot R, Zwinderman AE, Dijkman JH, Sterk PJ. Relationship between indices of parenchymal destruction and maximal airway narrowing in vivo in humans with $\alpha_{1}$-antitrypsin deficiency. Eur Respir J 1993; 6 (suppl.17): 229s.

27. Woolcock AJ, Boonsawat W, Donnelly P, Salome C. Relationship between lung elasticity and the maximal response plateau. Am Rev Respir Dis 1992; 145: A461.

28. Ludwig MS, Romero PV, Bates JHT. A comparison of the dose-response behaviour of canine airways and parenchyma. J Appl Physiol 1989; 67: 1220-1225.

29. Eidelman DH, Lei M, Ghezzo RH. Morphometry of methacholine-induced bronchoconstriction in the rat. J Appl Physiol 1993; 75: 1702-1710.

30. Brusasco V, Pellegrino R, Violante B, Crimi E. Relationship between quasi-static pulmonary hysteresis and maximal airway narrowing in humans. J Appl Physiol 1992; 72: 2075-2080.

31. Taylor IK, Shaw RJ. The mechanism of action of corticosteroids in asthma. Respir Med 1993; 87: 261-277.

32. Page C, Black J, (ed.). Airways and vascular remodelling in asthma and cardiovascular disease: implications for therapeutic intervention. Academic Press, London, 1994. (new book). In press. 